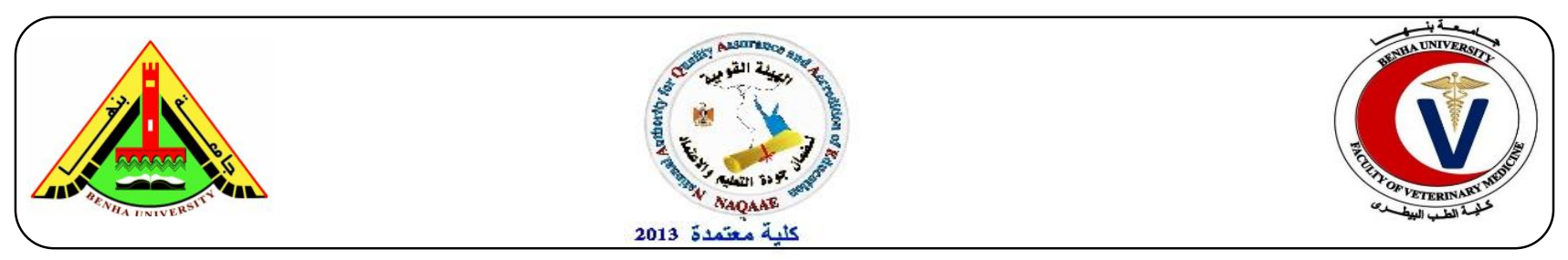

\title{
Interaction of some plant extracts with some antibiotics against Listeria monocytogenes from rabbits
}

\author{
Ashraf A. Abd El- Tawab ${ }^{1}$, Ahmed A. Ammar ${ }^{2}$, Ahmed M. Hamouda ${ }^{3}$ and Safinaz A. M.Elhawary ${ }^{3}$ \\ ${ }^{1}$ Bacteriology, Immunology and Mycology Department, Faculty of Veterinary Medicine, Benha University, Egypt. \\ ${ }^{2}$ Microbiology Department, Faculty of Veterinary Medicine, Zagazig University, Egypt. \\ ${ }^{3}$ Animal Health Research Institute, Zagazig branch.
}

\section{A B S T R A C T}

Multidrug-resistant bacteria strains is becoming a serious problem, so new technology applied plant extract as a natural antimicrobial source combined with antibiotics to overcome this problem by using new method as the Decimal Assay for Additivity (DAA) to define the end point for additivity as the interactions could be respectively defined as synergism or antagonism. The present study was carried out to evaluate the antimicrobial activity of five plant extracts prepared by the ultrasonic-assisted methanol extract (UAE) as zingeber officinalis (Ginger), camellia sinensis (Green tea), curcuma longa (Turmeric), pelargonium graveolens (Geranium) and thymus vulgaris (Thyme) combined with antibiotics like amoxicillin, doxycycline, gentamicin and difloxacin against 90 samples from dead and diseased rabbits with (10) isolates belonging to one Gram positive field strain of Listeria monocytogen by using agar diffusion method. The mean zone of inhibition (IZ) of methanol plant extracts and antimicrobial agents determined at different concentrations, Also, the minimum inhibitory concentration (MIC) (the lowest concentration which prevent visible growth of the bacteria) was determined for the tested plant extracts and the used antibiotics and for combination between them by the twofold dilution method, as the antimicrobial activities were assessed by using disc diffusion method. Total phenolic content (TPC) of plant extracts was determined by the FolinCiocalteu method, also the antioxidant activity of the extract was determined by the (DPPH) assay. Results revealed synergistic effects appear in thyme with amoxicillin by ratio (6:4),(5:5) while green tea with amoxicillin by ratio $(7: 3),(6: 4)$ and gentamicin by ratio $(6: 4)$ finally turmeric with doxycyclin by ratio (5:5), with gentamicin with (6:4), while with difloxacin by ratio(6:4), (5:5).

Keywords: Listeria monocytogens, plant extracts, Total phenolic compound, antioxidant activity.

\section{INTRODUCTION}

Listeriosis is an infection of human and animal importance. It is caused by Listeria monocytogens. Which widely distributed in the environment (Abd El-Motelib et al., 1990). The incorrect and overuse of existing antimicrobials is becoming a formidable threat in the fight against disease due to the emergence of multi-drug resistant strains. (Lambert, 2000 and Van Vuuren et al., 2009). Drug synergism between known antimicrobial 
agents and bioactive plant extracts is a novel concept and has been recently reported (Nascimento et al., 2000, Aqil et al., 2005, Betoni et al., 2006 and Mhanna and Adwan, 2008).

In the recent time, spread of multidrug resistance as a phenomenon among bacterial pathogens has been a major problem confronting the field of antibacterial chemotherapy (Stefanovic and Comic, 2012).

Listeria monocytogenes had resistance to one or two antimicrobials. Oxacillin resistance was the most common resistance phenotype against Listeria isolates. A medium prevalence of resistance to clindamycin and low incidence of resistance to tetracycline were also detected (Diego, et al., 2014).

The highest resistance of Listeria monocytogen against penicillin, erythromycin and nalidixic acid, with all Listeria spp displaying resistance, followed by ampicillin , trimethoprim, nitrofurantoin and cephalosporin Olanirian et al., (2015) .

To overcome this problem some medicinal plants also produce multidrug resistance inhibitors (Eze et al., 2013).

Methanol and aqueous extract of Camellia sinensis had antibacterial activity against Listeria monocytogenes. The methanol extracts of the test plant produce larger zones of inhibition against the bacteria than the water extract. (Mbata et al., 2008)

Myristica fragrans (Nutmeg) showed good anti-listerial activity, although, extracts of onion and pepper did not show any antibacterial activity against Listeria monocytogens (Indu et al., 2006)

Twenty eight essential oils had antibacterial properties, against four pathogenic bacteria (Escherichia coli, Listeria monocytogenes, Salmonella Typhimurium and Staphylococcus aureus) to determine the minimum inhibitory concentration (MIC) for each pathogen evaluated (Oussalah et al., 2007).
Thyme essential oil had antimicrobial effect against Listeria monocytogenes .It had synergestic effect with nisin against Listeria monocytogenes (Solomakos et al., 2008).

There were synergstic effects of the combination of subtilosin with natural antimicrobials of curcuminum against Listeria monocytogenes. (Tahar et al., 2010).

The Minimum Inhibitory Concentration (MIC) is the lowest concentration of an antimicrobial that will inhibit the visible growth of a microorganism by overnight incubation, usually reported as $\mathrm{mg} / \mathrm{L}$ (Delaquis et al., 2002) as represent a monitor resistance to antimicrobial agents and done by broth dilution methods (Handa et al., 2008).

Nowadays to overcome environmental pollution by aromatic plant extract residues, numerous studies focuses in recovering, recycling of residues as it has potential biological (Cioffi et al., 2010;Gavaric et al., 2015).As $99 \%$ of residues after extraction rich with secondary metabolites and bioactive compounds e.g. natural antioxidants and phenolic compounds (Zhao and Gao, 2014) which play an important role in protection against infection, preventing oxidation and degenerative diseases (Singleton et al., 1965 and Valko et al., 2006). Finally, this study was carried out to evaluate the Interaction of some plant extracts with some antibiotics against Listeria from rabbits and determination of MIC for each antibiotics and plant extracts by using DAA method to detect effect of interaction between antibiotics and plant extracts and detection of antioxidant and total phenolic compound.

\section{Materials and methods}

\subsection{Bacterial strains:}

a) Standard strain: The tested microorganisms were provided from the culture collections of the Microbiological Dept. National Research 
Center (NRC) Dokki, Giza, Egypt. These include Listeria monocytogens ATCC19112.

b) Field strain: 10 isolates out of 90 samples which were isolated from visceral organs of clinically diseased and dead rabbits of different ages reared in farms located in Sharkia and Dakahlia governorates.

Under aseptic condition, samples were transferred to bacteriological laboratory for bacteriological examination.

\subsection{Plants:}

a) Plant materials: Five plant samples: [Green tea leaves (Camellia sinensis), Thyme leaves (Thymus vulgaris), Ginger rhizomes (Zingiber officinale), Turmeric rhizomes (Curcuma longa) and Geranium leaves (Pelargonium graveolens).

b) Preparation of the ultrasonic-assist methanol $80 \%$ extract: Modern techniques as extraction by ultrasound to overcome (timesolvent) consuming and increase extraction efficiency (Betancount, 2008).

\subsection{Isolation and Identification of the suspected bacteria:}

\section{1-Media:}

A-Liquid media: Fraser broth, semisolid agar, $1 \%$ peptone broth, sugars (dextrose, maltose, sucrose, sorbitol, xylose, Lactose and mannitol). (Himedia).

B-Solid media: PALCAM, blood agar, triple sugar iron agar and urea agar base. (Himedia)

2-Reagents, chemicals and stains:

Kovac's, urea, Andrade's indicator, $\mathrm{H} 2 \mathrm{O} 2$, Gram's stain (Quinine et al. (2002) and Stanley, (1986).

3-Isolation and Identification of the suspected bacteria:

Samples were identified by gram staining, colony morphology, motility test (listeria show umbrella shape), catalase reaction, Voguesproskaur test, sugar Fermentation and the Christie- Atkins-Munch-Peterson (CAMP test). Quinine et al. (2002) and Warburton et al. (2003).

\subsection{Antimicrobial susceptibility testing:}

2.4.1. Disk Diffusion Method:

According to guidelines set by the Clinical Laboratory Standards Institute (CLSI, 2011) the diameters of the zones of inhibition were measured in millimeter and classified as resistant, intermediate or sensitive and done to every plant extract and, antibiotics alone and also to combination between them by disk diffusion method to detect the effect of ten standard antibiotic discs (Oxoid $®$ ) and five selected extracts against Listeria monocytogens.

2.4.2. Minimal inhibitory concentration (MIC):

The isolated strain matches the 0.5 McFarland standards $\left(1.5^{*} 10^{8} \mathrm{CFU} \mathrm{mL}^{-1}\right)$ and results of antibiotics and plant extracts showed no visible bacterial growth considered as MIC and interpreted with recommendations of the National Committee for Clinical Laboratory standards (CLSI,2011).

2.5. Evaluation of combined activity of antibiotics and plant extracts using Decimal Assay for Additivity (DAA):

As described by Sanders et al (1993) to detect end point for additivity so that interactions greater or less than additivity defined as synergism and antagonism respectively.

\subsection{Determination of total phenolic} compounds (TPC):

TPC measured by UV spectrophotometer Škerget et al.,( 2005) used Folin-Ciocalteu reagent (AOAS, 1990) results expressed as $\mathrm{mg}$ gallic acid equivalents (GAE) per gram of dry weight (mg GAE g-1 DW) using a calibration curve.

\subsection{Antioxidant DPPH radical-scavenging activity:}


The ability of the extracts for electron donation was measured by bleaching of the purple colored solution of DPPH' $(2,2$ - diphenyl-1picrylhydrazyl) to the yellow colored. (Gulcin et al., 2004) color intensity varies according to the amount of oxidant in the sample. The absorbance of this color is measured spectrophotometrically at $530 \mathrm{~nm}$ Dikilitas et al. (2011).

\section{RESULTS}

This study focused on the prevalence of Listeria monocytogenes and resistance patterns in Listeria monocytogenes. A total of 90 samples were aseptically collected from visceral organs of clinically diseased and dead rabbits of different ages reared in farms located in Sharkia and Dakahlia governorates with bacteriological examination of these Gram positive samples revealed the presence of 10 Listeriosis out of 90 specimens and isolates with percentages of $(11.11 \%)$ (Table1).

Fermentation and the Christie- Atkins-MunchPeterson (CAMP test)were used, under standard conditions (Table 3 ), as Listeria monocytogenes show positive results with Catalase and Voges-Proskauer, also positive result with methyl red and haemolysis test which recorded by Quinine et al. (2002) and Warburton et al. (2003)

Antimicrobial susceptibility testing showed the sensitivity of the Listeria monocytogenes strains tested, which exhibited respectively, as the highest sensitivity rate was recorded to flurophenicol, cefotaxime and erythromycin with (7, 6 and 5) of sensitive strains .The highest intermediate rate was recorded to amoxicillin and doxycycline with $(6,4$ and $)$ of intermediate strains. The highest resistant rate was recorded to colistin, and streptomycin with 9 , and 8 of resistant strains which shown in (Table 4).

As for Listeria monocytogenes, the extract of ginger with the lowest concentration had an
Inhibition Zone of $11 \mathrm{~mm}$, the green tea with the lowest concentration had an Inhibition Zone of $13 \mathrm{~mm}$, the thyme with the lowest concentration had an Inhibition Zone of 14 $\mathrm{mm}$, the gernium with the lowest Concentration had an Inhibition Zone of 10 $\mathrm{mm}$ and the turmeric with the lowest concentration had an Inhibition Zone of $13 \mathrm{~mm}$ showed in (Table 5).

On the other hand, the clear zones around each antibiotic discs were the zones of inhibition that indicated the extent of the test organism's inability to survive in the presence of the test antibiotic. So in this study the four antibiotics showed different Inhibition Zone on Listeria Monocytogenes like (13- $17 \mathrm{~mm})$ around amoxicillin, (11-16 $\mathrm{mm}$ ) around doxycycline, $(12 \mathrm{~mm})$ around gentamycin and (14- $22 \mathrm{~mm})$ around difloxacin (Table 5) .

Five plant extracts were subjected to a broth macro dilution assay and after twenty four hours observation of Listeria monocytogenes growth to determine the MIC values, as the MIC of Geranium was $2 \mu \mathrm{g} / \mathrm{ml}$ for Listeria monocytogenes, ginger was $>16 \mu \mathrm{g} / \mathrm{ml}$ for Listeria monocytogens, turmeric was $>16 \mu \mathrm{g} /$ $\mathrm{ml}$ for Listeria monocytogenes, thyme was 4 $\mu \mathrm{g} / \mathrm{ml}$ for Listeria monocytogens, and green tea was $>16 \mu \mathrm{g} / \mathrm{ml}$ for Listeria monocytogenes.

In this study, each 4 antibiotics was subjected to a broth macro dilution assay and after twenty four hours observation of bacterial growth to determine the MIC values on Listeria monocytogenes. MIC values of amoxicillin was $0.5 \mu \mathrm{g} / \mathrm{ml}$ for Listeria monocytogenes, doxycycline was $2 \mu \mathrm{g} / \mathrm{ml}$ for Listeria monocytogens, gentamicin was $8 \mu \mathrm{g} /$ $\mathrm{ml}$ for Listeria monocytogens and of difloxacin was $0.5 \mu \mathrm{g} / \mathrm{ml}$ for Listeria monocytogens (Table7).

Antimicrobial activities of methanol different plant extracts in combination with antimicrobial agents on selected Listeria 
Abd El- Tawab et al. (2018). BVMJ-35(2): 120-133

monocytogenes isolates as interactions between these components lead to antagonistic, additive and synergistic effects. Additive effect was observed when the combined effect was equal to the sum of the individual effects, antagonism was observed when the effect of one or both compounds was less when they were applied together than when individually applied and synergism was observed when the effect of the combined substances was greater than the sum of the individual effects.

Results of synergy between antibiotics/plant extract on Listeria monocytogenes were presented in table (8).

Then, Antibacterial activity of all Antibiotics alone and in combination with plant extracts on Listeria monocytogenes shown in (Table 8).

Amoxicillin shows synergistic action in combination of with green tea by level $(7: 3)$ and by (6:4), also shows synergistic action in combination with thyme by level $(6: 4)$ and
(5:5). While doxycycline shows synergistic action in combination with turmeric by level by (5:5), while gentamicin shows synergistic action in combination with green tea by level (6:4), also shows synergistic action in combination with turmeric by level (6:4). Finally difloxacin shows synergistic action in combination with turmeric by level $(6: 4),(5: 5)$.

According to total phenolic compound (Table 9) illustrated that thyme and geranium had high phenolic compounds than green tea. Finally turmeric and ginger had nearly the same results with respective values of 253.01, 219.3, 190.33, 43.96 and $41.92 \mathrm{mg} \mathrm{GAE} \mathrm{g}^{-1}$ extract TPC expressed as Gallic acid equivalent (GAE) was calculated using the following linear equation based on the calibration curve.

According to DPPH result, ginger and turmeric showed higher extension than green tea than geranium, Also, thyme extract had shown lower extent of DPPH neutralization (EC50 = $128.49 \mathrm{mg} / \mathrm{mL}$ ) than oil obtained (Fig.1).

Table 1: Number of Listeria isolates obtained from various specimens collected from different localities in Sharkia and Dakahlia governorates.

\begin{tabular}{lccc}
\hline & Locality & No. of cases & $\begin{array}{c}\text { Listeria } \\
\text { monocytogens } \\
\text { Dakhlia governate }\end{array}$ \\
Sharkia governate & $\begin{array}{c}\text { Private farms } \\
\text { (Gamsa,Sherbin) } \\
\text { Private farms in } \\
\text { Total }\end{array}$ & 50 & 4 \\
\hline
\end{tabular}


Table 2: List of the methanolic extract obtained from different plant parts $\mathrm{g} / \mathrm{ml}$ spices in stock solution.

\begin{tabular}{lllccc}
\hline \multicolumn{1}{c}{ Scientific name } & \multicolumn{1}{c}{ Family } & Local name & $\begin{array}{c}\text { Wt. of } \\
\text { extract in } \\
\text { tube }(\mathrm{g})\end{array}$ & $\begin{array}{c}\text { Wt. of empty } \\
\text { tube }(\mathrm{g})\end{array}$ & $\begin{array}{c}\text { Total Wt. } \\
\text { of extract } \\
(\mathrm{g})\end{array}$ \\
\hline Pelargonium graveolens & Geraniaceae & Geranium & 138.0542 & 134.5216 & 3.53 \\
Camellia sinensis & Theaceae & Green tea & 172.3789 & 169.9189 & 8.9 \\
Zingiber officinale & Zingiberiaceae & Ginger & 177.5154 & 176.9858 & 1.02 \\
Thymus vulgaris & Thymeleaceae & Thyme & 191.9960 & 187.3328 & 4.66 \\
Curuma longa & Zingiberiaceae & Turmeric & 193.6245 & 192.6999 & 0.42 \\
\hline
\end{tabular}

Table 3a: Morphological and Biochemical characteristics of isolated Listeria monocytogenes.

\begin{tabular}{cc}
\hline Growth on enriched fraser broth & Blackening \\
\hline Growth on Palcam media & $\begin{array}{c}\text { Gray green colonies surrounded by dark } \\
\text { brown to black halos in medium } \\
\text { Pram staining }\end{array}$ \\
Catalase & Positive \\
Oxidase & Negative \\
Indole & Negative \\
Methyl Red & Positive \\
Voges-Proskauer & Positive \\
Urease production & Negative \\
Citrate & Negative \\
Haemoylsis & Positive \\
\hline
\end{tabular}

Table 3b: Results of carbohydrate fermentation test for Listeria monocytogenes.

\begin{tabular}{cc}
\hline CARBOHYDRATES TEST & Result \\
\hline Rhamnose & Positive \\
Xylose & Negative \\
Glucose & Positive \\
Manitol & Negative \\
Arabinose & Positive \\
Sorbitol & Positive \\
Fructose & Positive \\
\hline
\end{tabular}


Abd El- Tawab et al. (2018). BVMJ-35(2): 120-133

Table 4: Antimicrobial susceptibility of Listeria spp. by agar disc diffusion method.

\begin{tabular}{lllll}
\hline \multicolumn{1}{c}{ Antimicrobial agents } & $\begin{array}{l}\text { Antibiotic } \\
\text { disc/conc. }(\mu \mathrm{g})\end{array}$ & S & I & R \\
& & & & \\
\hline Amoxicillin & AML-25 & 2 & 6 & 2 \\
Colistin & CT-10 & 0 & 1 & 9 \\
Difloxacin & INN-5 & 1 & 5 & 4 \\
Doxycycline & DO-30 & 2 & 4 & 4 \\
Gentamycin & CN-10 & 3 & 4 & 3 \\
Erythromycin & E-15 & 5 & 3 & 2 \\
Flurophenicol & F-30 & 7 & 0 & 3 \\
Cefotaxime & CTX-30 & 6 & 0 & 4 \\
Streptomycin & S-10 & 0 & 2 & 8 \\
\hline
\end{tabular}

R (resistance), S (susceptibility), I (intermediate)

Table 5: Zone of inhibition $(\mathrm{mm})$ of antibiotics and extracts alone and in combination on field strain of Listeria monocytogenes.

\begin{tabular}{cccccccccc}
\hline Isolates & \multicolumn{7}{c}{ Inhibition zone ( mm ) } \\
& \multicolumn{7}{c}{ Antibiotics alone } \\
Plants & Plant & AML/ & DO/ & CN/ & INN/2 & & \\
& & 18 & 18 & 15 & 2 & AML & DO & CN & INN \\
& & $(\mathrm{mm})$ & $(\mathrm{mm})$ & $(\mathrm{mm})$ & $(\mathrm{mm})$ & & & & \\
Geranium & 10 & 13 & 11 & 12 & 22 & 16 & 19 & 13 & 20 \\
Green tea & 13 & 15 & 14 & 12 & 15 & 19 & 12 & 16 & 14 \\
Ginbger & 11 & 16 & 14 & 12 & 16 & 16 & 13 & 11 & 22 \\
Thyme & 14 & 17 & 16 & 12 & 14 & 18 & 16 & 17 & 22 \\
Turmeric & 13 & 15 & 13 & 12 & 19 & 14 & 18 & 15 & 22 \\
\hline
\end{tabular}

AML: amoxicillin.

$\mathrm{CN}$ : gentamicin.

DO : doxycyciline. INN: difloxacin. 
Table 6: Minimum inhibitory concentration (MIC) of plant extracts on Listeria monocytogenes (Field and Standard Strains).

\begin{tabular}{lll}
\hline Plants & Listeria monocytogenes & MIC \\
& & $\mu \mathrm{g} / \mathrm{ml}$ \\
Geranium & Field Strain & 2 \\
& Standard strain & 1 \\
Green tea & Field Strain & $>16$ \\
& Standard strain & 8 \\
Ginger & Field Strain & $>16$ \\
\multirow{2}{*}{ Thyme } & Standard strain & 8 \\
& Field Strain & 4 \\
Turmeric & Standard strain & 2 \\
& Field Strain & $>16$ \\
\hline
\end{tabular}

Table 7: Minimum inhibitory concentration (MIC) of antibiotics on Listeria monocytogens (field and standard strains).

\begin{tabular}{ccc}
\hline Antibiotic & Listeria monocytogenes & MIC \\
& & $\mu \mathrm{g} / \mathrm{ml}$ \\
Amoxicillin (20\%) & Field Strain & 0.5 \\
& Standard strain & 0.25 \\
doxcyciline (20\%) & Field Strain. & 2 \\
Gentamicin (10\%) & Standard strain & 1 \\
difloxacin (10\%) & Field Strain & 8 \\
& Standard strain & 0.5 \\
& Field Strain & 0.5 \\
& Standard strain & 0.25 \\
\hline
\end{tabular}

Table 8: Combination activity of antibiotics with extracts using Decimal Assay for Additivity (DAA). Listeria monocytogenes

\begin{tabular}{|c|c|c|c|c|c|c|}
\hline \multirow{2}{*}{ Plant extracts } & \multirow{2}{*}{ Antibiotics } & \multicolumn{3}{|c|}{ DAA } & MIC & \multirow{2}{*}{ Effect } \\
\hline & & $\mathrm{AB}$ & $\mathrm{E}$ & DAA & $\mathrm{AB}$ alone & \\
\hline \multirow[t]{2}{*}{ Thyme } & a) Amoxicillin & 6 & 4 & \multirow{2}{*}{0.55} & 1 & \multirow[t]{2}{*}{ Synergy (S) } \\
\hline & & 5 & 5 & & 1 & \\
\hline
\end{tabular}


Abd El- Tawab et al. (2018). BVMJ-35(2): 120-133

$\begin{array}{lcccccc}\text { Green tea } & \text { a) Amoxicillin } & 7 & 3 & & & \\ & 6 & 4 & 0.25 & 0.5 & \text { Synergy (S) } \\ & \text { b) Gentamicin } & 6 & 4 & 4 & 8 & \\ \text { Turmeric } & \text { a) Doxycycline } & 5 & 5 & 0.25 & 0.5 & \text { Synergy (S) } \\ & \text { b) Gentamicin } & 6 & 4 & 2 & 4 & \end{array}$

Table 9: Yield of extracts $(\mathrm{g} / 100 \mathrm{~g})$ for different plants.

\begin{tabular}{cccc}
\hline Plants & extract yield & \% Extract & TPC mg GAE/g extract \\
\hline Green tea & 8 & 40 & 190.33 \\
Thyme & 4.66 & 23.3 & 253.01 \\
Ginger & 1.02 & 5.1 & 43.96 \\
Turmeric & 0.42 & 2.1 & 41.92 \\
Geranium & 3.53 & 17.65 & 219.38
\end{tabular}

TPC: Total phenolic compound, GAE: Gallic acid equivalents

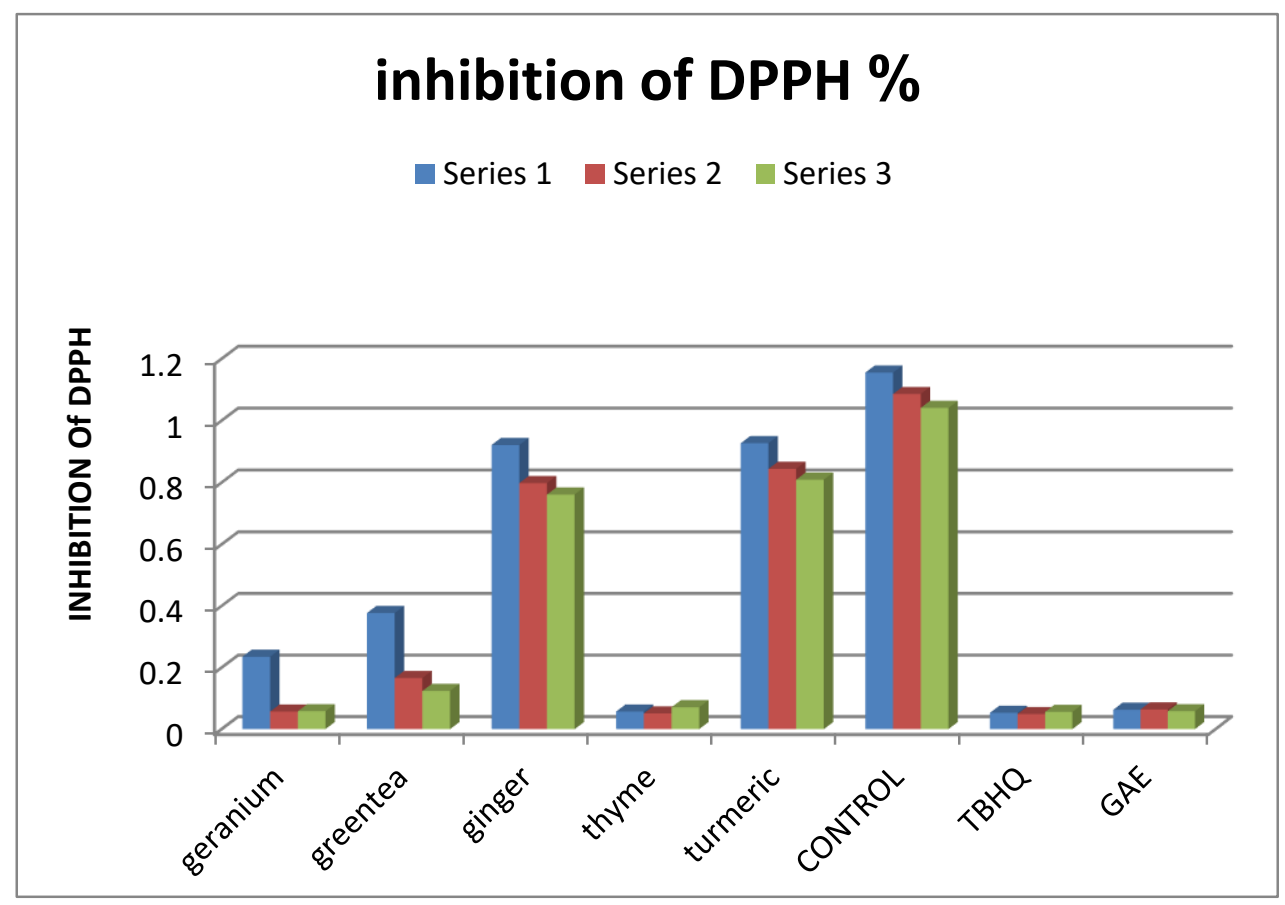

Fig.1. Antioxidant DPPH radical-scavenging activity.

GAE: Gallic acid equivalents.

TBHQ: Tert-butyl hydroquinone. 


\section{DISCUSSION}

L. monocytogenes still occurs at a low prevalence Diego et al., (2014). Biochemical test as catalase, Voges-Proskauer,methyle red and hemolysis test with recorded results agreed with Quinine et al. (2002) and Warburton et al. (2003).

Antimicrobial susceptibility testing showed the highest sensitivity rate of the Listeria monocytogenes strains to flurophenicol, cefotaxime and erythromycin this result agreed with Escolar et al. (2017).

The highest intermediate rate of Listeria monocytogenes was recorded to amoxicillin and doxycycline of intermediate strains this result disagreed with Vitas etal (2007)

The Zone of Inhibition was obtained for Listeria monocytogenes to show antibacterial activity of different plant extracts and antibiotics on it and the results revealed that the diameter Inhibition Zone of ginger(11) $\mathrm{mm}$, disagreed with Hossain et al. (2017), the diameter Inhibition Zone of green tea (13) $\mathrm{mm}$ , Inhibition Zone of thyme(14)mm, Inhibition Zone of geranium pelargonium(10)mm disagreed with Ghannadi et al (2012) .

Inhibition Zone of the four antibiotics revealed that diameter of Inhibition Zone for Listeria Monocytogens ranged from (13-17 $\mathrm{mm})$ around amoxicillin, (11-16 $\mathrm{mm}$ ) around doxycycline, $(12 \mathrm{~mm})$ around gentamicin and (14- $22 \mathrm{~mm}$ ) around difloxacin, this result agreed with Hossain et al. (2017).

The MIC values for Listeria monocytogenes revealed that MIC value of amoxicillin was 0.5 $\mu \mathrm{g} / \mathrm{ml}$ for Listeria monocytogenes this result agreed with morvan et al. (2010), ( DO) doxycycline was $2 \mu \mathrm{g} / \mathrm{ml}$ for Listeria monocytogens, (CN) gentamicin was $8 \mu \mathrm{g} / \mathrm{ml}$ for Listeria monocytogenes and of ( INN)
Difloxacin was $0.5 \mu \mathrm{g} / \mathrm{ml}$ for Listeria monocytogenes this result disagreed with (Siporin et al., 1990).

Antibacterial activity of all Antibiotics alone and in combination with plant extracts on Listeria monocytogenes revealed that amoxicillin shows synergistic action in combination of with green tea by level $(7: 3)$ and by (6:4) this result agreed with Wanda (2018).

Activity of extract compared to unstable oil is probably due to presence of nonvolatile phenol compounds. In addition, some of the compounds with a different polarity, which are present in very small amounts in the extract, are also able to contribute to better an oxidative activity of extract. Some compounds can originate in extract during hydrolysis or other processes of decomposition. Some chemical reactions initiated by heating can also drive up to activities changes of complex extract, composed of a number of compounds with different chemical and physical properties Singh et al. (2005).

The free radical activity of the plant extracts was performed according to the DPPH free radical method, described by Brand-Williams et al. (1995).

It can be noticed that the degree of DPPH neutralization depended on incubation time, for all investigated concentrations of oil. The highest degree of DPPH radicals' neutralization is for 60 minutes incubation.

\section{Conclusion}

The demonstration of synergistic activity by the antibiotic-plant against Gram positive bacteria is an indication that the plant can be a source of bioactive substances that could possess broad spectrum of activity most especially when it is combined with antibiotic. Thus, there is increasing need for researchers 
to investigate the synergistic capacity of plants or other natural products, independent of the antimicrobial activity. These findings also suggested that the need for understanding of synergism mechanism is fundamental to development of pharmacological agents to treat diseases by various bacteria using medicinal plants in combination with antibiotics.

\section{REFERENCES}

Abdel Moteleb,T.Y; B. Salem and ElZanaty,K. (1990): Outbreak of listeriosis in rabbits .4th Sci. Congr., Fc. Vet. Med. Assuit.University pp.10451049.

AOAS (1990): In Official methods and recommended practices of the American Oil Chemists' Society $\left(4^{\text {th }}\right.$ ed.). Champaign: American Oil Chemists' Society.

Aqil, F., Khan, M.S.A., Owais, M. and Ahmad, I. (2005): Effect of certain bioactive plant extracts on clinical isolates of $\beta$ lactamase producing methicillin resistant Staphylococcus aureus. J. of Basic Microbiol, 45:106-114.

Betancourt A.O., (2008): Analyze, extraction et récupération de poly-3hydroxybutyrate présent dans la biomasse. Université du Québec à Montréal Thesis; pp 45-55.

Betoni, J.E.C., Mantovani, R.P., Barbosa, L.N., Di Stasi, L.C. and Fernandes, J.A. (2006): Synergism between plant extract and antimicrobial drugs used on Staphylococcus aureus diseases. Mem.Inst. Oswaldo Cruz. Rio de Janeiro, 101(4): 387-390.

Brand- W, Cuvelier ME and Berset C. (1995): Use of a free radical method to evaluate antioxidant activity. Food Sci Technol. Vol, 28:25-30.

Cioffi, M.B., Martins, C and Bertollo, L.A.C. (2010): Chromosomal spreading of associated transposable elements and ribosomal DNA in the fish Erythrinus erythrinus. Implications for genome change and karyoevolution in fish. BMC Evolutionary Biol., 10:271

CLSI, (2011): Clinical and Laboratory Standards Institute. Performance Standards for Antimicrobial Susceptibility Testing; Twenty-First Informational Supplement. CLSI document M100-S21 (ISBN 1-56238742-1). Clinical and Laboratory Standards Institute, 940 West Valley Road, Suite 1400, Wayne, Pennsylvania 19087 USA, 2011.

Delaquis, P.J., Stanich, K., Girard, B., and Mazza, G. (2002): Antimicrobial activity of individual and mixed fractions of dill, cilantro, coriander and eucalyptus essential oils. Int.J. Food Microbiol. , 74: 101-109.

Diego G., Ester A., Noelia M.,Juan J.C.,Carimina R.,Agustin A.,Javier Y.,(2014) : Antimicrobial resistance of Listeria monocytogenes and Listeria innocua from meat products and meatprocessing environment. Volume 42, September 2014, Pages 61-65.

Dikilitas, M., Guldur, M.E., Deryaoglu, A., and Erel, O., (2011): Antiox-idant and oxidant levels of pepper (Capsicum annuum cv. 'Charlee') infected with pepper mild mottle virus. Not. Bot. Horti Agrobo. 39, 58-63.

Escolar C., Gómez D., García M.,D.,C.,R., Conchello P., and Herrera A.,(2017): Antimicrobial Resistance 
Profiles of Listeria monocytogenes and Listeria innocua Isolated from Readyto-Eat Products of Animal Origin in Spain. Foodborne Pathogens and Dis, 14(6):357-363.

Eze, E., Oruche, N., and Eze, C. (2013): Interaction of the extracts of three medicinal plants with antibiotics against some antibiotic resistant bacteria. Acad J., 8(28): 1360-1367.

Gavarić, N.,Gavarić, J.,Kovač, N.,Kretschmer, N., Kladar, S., Možina, F.,\& Bucar.(2015).Natural products as antibacterial agents antibacterial potential and safety of post-distillation and waste material from Thymus vulgaris L., Lamiaceae .Journal of Essential Oil-Bearing Plants, 10.1080/0972060X.2015.971069

Ghannadi, A., Bagherinejad, MR., Abedi, D., Jalali, M., Absalan, B., and Sadeghi N. (2012): Antibacterial activity and composition of essential oils from Pelargonium graveolens L'Her and Vitex agnuscastus L. Iran J Microbiol. 2012 Dec, 4(4): 171-176.

Gulcin,I., Kufrevioglu, O.I., Oktay, M. and Buyukokuroglu, M.E. (2004): Antioxidant, antimicrobial, antiulcer and analgesic activities of nettle (Urtica dioica L.). J. Ethnopharmacolo., 90: 205-215.

Handa, S.S., Khanuja, S.P.S., Longo, G. and Rakesh, D.D. (2008): Extraction Technologies for Medicinal and Aromatic Plants, ( $1^{\text {st }}$ ed.n), no. 66. Italy: United Nations Industrial Development Organization and the International Centre for Science and High Technology.
Hossain M.N., Talukder A., Barman T., Rahaman M., M., Begum S. and Ahmed M., M., (2017): Antimicrobial Activity of Spices against Listeria monocytogenes Isolated from Dairy Products. Bangladesh Journal of Industrial Microbiology and Biotechnology, 1(1): 29-38.

Indu, M.N., Hatha, A. A.M., Abirosh, C., Harsha, U. and Vivekanandan, G. (2006): Antimicrobial activity of some of the south-Indian spices against serotypes of Escherichia coli, Salmonella, Listeria monocytogenes and Aeromonas hydrophila. Braz. J. Microbiol., 37, 153-158.

Lambert, R.J.W. (2000): Susceptibility testing: inoculum size dependency of inhibition using the Colworth MIC technique. $J$. Appl. Microbiol., 89:275-279.

Mbata, T.I., Debiao, L.U. and Saikia, A. (2008): Antibacterial activity of the crude extract of Chinese green tea (Camellia sinensis) on Listeria monocytogenes. African Journal of Biotechnology, 7(10), 1571-1573.

Mhanna, M.and Adwan, G. (2008): Synergistic Effects of Plant Extracts and Antibiotics on Staphylococcus aureus Strains Isolated from Clinical Specimens Middle-East. Journal of Scient.Res., 3(3): 134-139.

Morvan, A., Moubareck, C., Leclercq, A., Herve'-Bazin, M. , Bremont, S. , Lecuit, M., Courvalin, P. and Monnier A. Le (2010): Antimicrobial Resistance of Listeria monocytogenes Strains Isolated from Humans in France. Antimicrob. Ag. \&Chemother. 54(6), 2728-2731.

Nascimen9to, G.G.F., Locatelli, J., Freitas, P.C. and Silva, G.L. (2000): 
Abd El- Tawab et al. (2018). BVMJ-35(2): 120-133

Antibacterial activity of plant extracts and phytochemicals on antibiotic resistant bacteria. Braz. J. of Microbiol., 31(4):247-256.
Olaniran
A.
O., $\quad$ Nzimande

S.B.T., Ndumiso G., and Mkize N.G., (2015): Antimicrobial resistance and virulence

signatures

of Listeria and Aeromonas species

recovered from treated wastewater effluent and receiving surface water in Durban, South Africa BMC. Microbiology201515:234 https://doi.org/10.1186/s12866-0150570-x.

Oussalah, M.; Caillet, S.; Saucier, L. and Lacroix, M. (2007): Inhibitory effects of selected plant essential oils on the growth of four pathogenic bacteria: $E$. coli O157:H7, Salmonella Typhimurium, Staphylococcus aureus and Listeria monocytogenes. Elsever; 18(5), 414-420.

Quinine, P.J.; Markery, B.K.; Carter, M.E.; Donnelly, W.J. and Singh, A., Chan, J., Chern, J.J. and Choi, K.W. (2002): Genetic interaction of Lobe with its modifiers in dorsoventral patterning and growth of the Drosophila eye. Genetics, 171(1):169-183.

Sanders, CC, Sanders, WE (Jr), and Moland, ES. (1993): Decimal assay for additvity of drugs permits delineation of synergy and antagonism. Antimicrob. Agents Chemother; 37:260-264.

Singh, A., Chan, J., Chern, J.J. and Choi, K.W. (2005): Genetic interaction of Lobe with its modifiers in dorsoventral patterning and growth of the Drosophila eye. Genetics, 171(1): 169-183.
Singleton, V.L. and Rossi, J.A. (1965): Colorimetry of total phenolics with phosphomolybdic phosphotungstic acid reagents. Am. J. Enol. Viticult, 16: 144158.

Siporin C., Heifez C., L. and Domagala J., M., (1990): Book of The new generation of Quinols .Marsel Dekker, INC, and Basel Newyork.

Škerget, M., Kotnik, P., Hadolin, M., RižnerHraš, A., Simonič, M. and Knez, Ž. (2005): Phenols, proanthocyanidins, flavones and flavonols in some plant materials and their antioxidant activities. Food Chem., 89: 191-198.

Stanley, M.D. (1986): Listeriosis in current veterinary therapy, food animal practice 2nd Ed. By J.L. Howard 562-565 V.B. Saunders Company.

Stefanovic, O. and Comic, L. (2012): Synergistic Antibacterial Interaction between Melissa officinalis extracts and antibiotics. J. Appl. Pharmaceut. Sci., 2(1):1-5.

Tahar A., Katia S., N., Yuwen W., Qingrong H., Michael L. C., (2010): Antibacterial Activity of Subtilosin Alone and Combined with Curcumin, Poly-Lysine and Zinc Lactate Against Listeria

monocytogenes Strains. Springerlink December, Volume 2, Issue 4, pp 250257|

Valko., M., Rhodes, C.J., Moncol, J. and Izakovic, M. (2006): Free radicals, metals and antioxidants in oxidative stress-induced cancer. Mini-review. Chem. Biol. Interact., 160:1-40.

Van Vuuren, S.F., Suliman, S. and Viljoen, A.M (2009): The antimicrobial activity of four commercial essential oils in 
combination with conventional antimicrobials. Wiley Online Library, 48(4):440-446.

Vitas A.I. , Sánchez R., M., Aguado V. and García-Jalón I. (2007): Antimicrobial susceptibility of Listeria monocytogenes isolated from food and clinical cases in Navarra, Spain. J Food Prot., 70(10):2402-6.

Wanda C. R., (2018): Green Tea Catechins Their Use in Treating and Preventing Infectious Diseases. Biomed Res Int., Published online 2018 Jul 17. Doi: 10.1155/2018/9105261.

Warbureton, D.; Boville, Anne, PagottoF., Daley Eliane and Chow. Cindy (2003): The detection of listeria spp. In foods and environmental samples using pal cam broth. Health products and food Branch (HPFB), Ottawa, Ontario.

Zhao Y. and Gao Y. (2014): Self-processing of ribozyme-flanked RNAs into guide RNAs in vitro and in vivo for CRISPRmediated genome editing. J. Integr. Plant Biol., 56(4). 